\title{
Grip Strength: Influence of Head-Neck Position in Normal Subjects
}

\author{
N.Sundaramurthy Senthil Kumar ${ }^{\mathrm{a}, \mathrm{c}}$, C. Reuban Daniel ${ }^{\mathrm{b}}$, \\ Merlyn Hilda ${ }^{\text {, Rajalakshmi Dharmarajan }}{ }^{\mathrm{a}}$
}

\begin{abstract}
Background: The aim of this study was to investigate whether head-neck $(\mathrm{H}-\mathrm{N})$ position affects grip strength in healthy young adults and to find out, which $\mathrm{H}-\mathrm{N}$ position have the greatest influence on grip strength.
\end{abstract}

Methods: Eighty male and female students volunteered as subjects. The dominant hand was used to apply tension to the lever of a Jamar dynamometer. The data collection procedures followed American Society of Hand Therapists standardized grip-strength testing guidelines, with the except for $\mathrm{H}-\mathrm{N}$ position. The maximal grip strength was measured at $\mathrm{H}-\mathrm{N}$ in neutral, rotation to the left and rotation to the right.

Results: The results were analyzed using independent ' $t$ ' test to compare the height and weight between groups. To compare the maximal grip strength between $\mathrm{H}-\mathrm{N}$ position one-way analysis of variance and Tukey HSD was used. The result showed that maximal grip strength in the right dominant was significantly highest at $\mathrm{H}-\mathrm{N}$ rotated to left at $\mathrm{P}<0.05$.

Conclusions: The highest maximal grip strength obtained at $\mathrm{H}-\mathrm{N}$ rotated to left, showed that for accurate assessment and rehabilitation, the $\mathrm{H}-\mathrm{N}$ should be positioned opposite to the tested extremity which could be due to the influence of ATNR.

Keywords: Grip strength; Asymmetrical tonic neck reflex; Dynamometer; Head-neck position

Manuscript accepted for publication June 22, 2012

${ }^{a}$ Lecturer, Faculty of Therapeutic sciences, ASEAN Metropolitan University College, Malaysia, bPhysiotherapist, Kothara Community Hospital, The Leprosy Mission Trust, India.

${ }^{\mathrm{c} C}$ Corresponding author: N.Sundaramurthy Senthil Kumar, Faculty of Therapeutic sciences (Physiotherapy), Asean Metropolitan University College, Jalan Kemacahaya, Batu 9, Cheras, Selangor, 43200, Malaysia. Email: nsshakthi@gmail.com

doi: $10.4021 / \mathrm{jnr} 117 \mathrm{w}$

\section{Introduction}

Magnus and de Kleijn demonstrated the existence of the tonic neck reflex (TNR) [1]. They noted that head position influenced limb muscle tone in decerebrate animals. Although the reflex may affect all four limbs, its influence is greater on the upper extremities than on the lower extremities. Evidence of the TNR disappears earlier in the lower extremities than in the upper extremities. The TNR has both a symmetrical (STNR) and an asymmetrical (ATNR) component [2].

Persistence of this reflex in humans beyond one year of age often has been interpreted to indicate neurological or maturational dysfunction. George administered grip strength tests to children aged 5 to 7.5 years using both their preferred and non preferred hands while varying the H-N position. She found that the left tonic neck posture most nearly approached the direction of changes in grip strength predicted by the TNR and was more evident in right-handers than in left-handers [3]. Parmenter studied children aged 6 to just under 10 years and concluded that the ATNR could be elicited when the H-N were rotated to either side while the children were in the hand knee kneeling position. This reflex was more evident with younger, less mature children than with older, more mature children [4]. In addition, consistent with the findings by George, the reflex was inhibited more easily when the H-N were rotated to the right side than to the left side.

Wells demonstrated that the TNR and labyrinthine reflexes could be elicited in healthy adults [5]. Ikai tested male subjects ranging in age from 7 to 25 years and observed a decrease in the magnitude of the response with age [6].

Tokizane et al, using electromyographic techniques, demonstrated a change in motor unit activity attributable to change in the $\mathrm{H}-\mathrm{N}$ position in infants, healthy adults, and neurologically impaired persons [7]. Hellebrandt et al clearly demonstrated that the TNR patterning is elicited under heavy resistance exercises augmenting the work output [8]. Fukuda, analyzing isotonic movement, observed evidence of the facilitatory effects of the TNR in healthy adults [9]. In contrast to Fukuda's study, Geddes and O'Grady, working with persons from 20 to 32 years of age, found no evidence 
Table 1. Weight Compared Between Men and Women

\begin{tabular}{llll}
\hline Group & Male & Female & \\
\hline Mean & 60.10 & 56.25 & $\mathrm{t}=2.0391$ \\
SD & 10.30 & 6.04 & $\mathrm{df}=78$ \\
Sem & 1.63 & 0.95 & $\mathrm{SED}=1.888$ \\
$\mathrm{~N}$ & 40 & 40 & $\mathrm{P}=0.0448$ \\
\hline
\end{tabular}

of STNR or ATNR during isotonic physical activity [10]. A review of the literature has revealed the existence of the TNR in young children and in persons who are under stress or neurologically impaired.

Grip strength, which was defined as a forcible activation of fingers and thumb acting against the palm for transmitting force to an object is frequently used in rehabilitation settings in order to monitor patient progress [11]. Maximal grip strength was also defined as the maximal force exerted to grip, and is an indirect measurement of the strength of contraction of all muscles that flex the fingers. The hand is an important tool through which we control and manipulate our environment, and communicate ideas and talents. The normal functional position of the hand involves power grip. It was also reported that body posture and angular positions of the shoulder, the elbow, the forearm, the wrist joint, the metacarpophalangeal joint and the interphalangeal joints and upper limb position has been found to affect maximal grip strength $[12,13]$.

The purpose of this study was to determine which H-N position, if any, have the greatest facilitatory effect on grip strength in healthy young adults.

\section{Method}

\section{Subjects}

Eighty volunteered students (40 men, 40 women) between
Table 2. Height Compared Between Men and Women

\begin{tabular}{llll}
\hline Group & Male & Female & \\
\hline Mean & 1.66 & 1.62 & $\mathrm{t}=2.55$ \\
SD & 0.07 & 0.065 & $\mathrm{df}=78$ \\
Sem & 0.0113 & 0.0103 & $\mathrm{SED}=0.015$ \\
$\mathrm{~N}$ & 40 & 40 & $\mathrm{P}=0.0127$ \\
\hline
\end{tabular}

the ages of 17 and 25 years serve as subjects for this study. After each subject completed the research consent form, the procedure to be followed were explained and demonstrated. The standard adjustable Jamar handle dynamometer was the instrument used for this study. The inclusion criteria for the study were dominant right hand without orthopedic and neurological disorder or injuries to the dominant extremity by self-report. Dominant hand was defined as the one preferred for daily activities like writing and eating and for handling heavy objects. We reviewed grip strength at each of the H-N positions (neutral, rotation left, and rotation right).

\section{Procedure}

The design for this study was expost-factorial, in which each subject was seen once for the measurement. Jamar handle dynamometer is reliable, and preferably used for clinical measurement because it is cheap and easy to handle and has been found to give the most accurate measure of grip strength [14].

Prior to grip strength test, the procedure of assessment was demonstrated to subjects. The data collection procedures followed American Society of Hand Therapists standardized grip-strength testing guidelines, with the except for H-N position. The subjects were seated comfortably on a back rest chair, placing their dominant hand on the flat table with a wrist stabilizer, and later grip the hand dynamometer, while the non-dominant hand is positioned on the contralateral thigh. Each subject is asked to perform one trial under

Table 3. Tests of Between-Male Subjects Effects

\begin{tabular}{cccccc}
\hline Source of variation & Sum of squares & df & Mean square & F & P \\
\cline { 1 - 4 } between & 394.8 & 2 & 197.4 & & \multirow{2}{*}{$\begin{array}{l}\text { P.934 } \\
\text { error }\end{array}$} \\
2911.0 & 117 & 24.88 & & 0.0006 \\
\hline
\end{tabular}


Table 4. Tests of Between-Female Subjects Effects

\begin{tabular}{|c|c|c|c|c|c|}
\hline Source of variation & Sum of squares & df & Mean square & $\mathbf{F}$ & $\mathbf{P}$ \\
\hline between & 666.7 & 2 & 333.4 & \multirow{3}{*}{45.86} & \multirow{3}{*}{0.0001} \\
\hline & & & & & \\
\hline error & 850.4 & 117 & 7.269 & & \\
\hline
\end{tabular}

each $\mathrm{H}-\mathrm{N}$ position with one minute rest period in order to prevent the practice that might mask the effect of the reflex and to reduce fatigue. The subjects were instructed to apply maximum grip on the dynamometer, in three different $\mathrm{H}-\mathrm{N}$ positions, and the instruction given was "grip".

The maximal grip strength was noted in Kilograms $(\mathrm{kg})$ with the subject exerting maximum effort to grip with no verbal encouragement. The order of testing grip with different $\mathrm{H}-\mathrm{N}$ position was randomized and varied between subjects to minimize fatigue and the practice effect. Periodic calibration of the instrument was done to ensure precision throughout the duration of the study.

\section{Data analysis}

The grip strength data were analyzed by an analysis of variance (ANOVA) for repeated measures followed by a Tukey HSD test. P values equal to or less than 0.05 were accepted

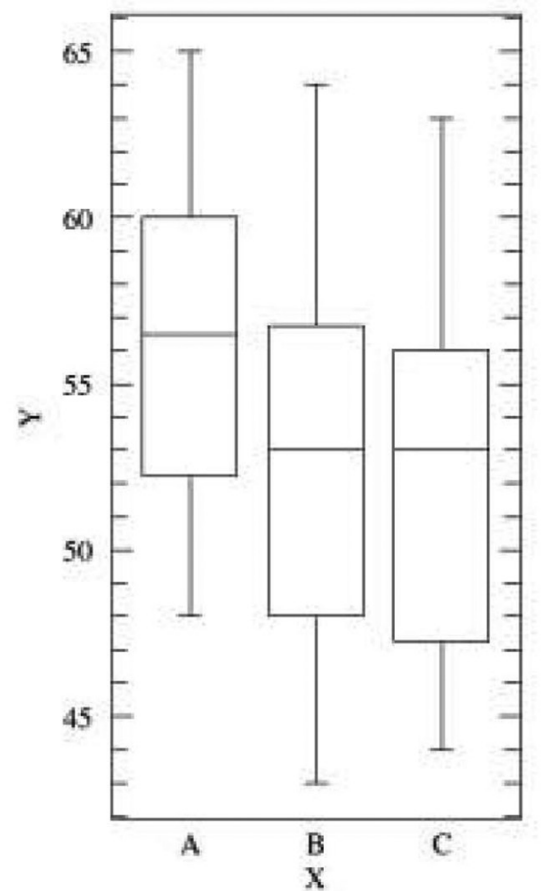

Figure 1. (Male) $X$ axis- $H-N$ position, $A$ : rotation to left; $B$ : neutral; C: rotation to right; $Y$ axis- grip strength in Kgs. as significant $(\mathrm{P}<0.05)$. The mean valves of height and weight for the male subjects were higher and more variable than that of female subjects. The data, therefore, were analyzed separately for male and female because combining the data may mask the changes obtained for the female subjects.

\section{Results}

A total of 80 students participated in this study. Their age range was between 17.0 and 25.0 years (male $18.0-25.0$ years, female 17.0 - 25.0 years). They weighed between 43.0 and $81.0 \mathrm{~kg}$. (Male, 48.0 - $81.0 \mathrm{~kg}$, Female, 43.0 - $67.0 \mathrm{~kg}$ ) and their height was between $1.48 \mathrm{~m}$ and $1.82 \mathrm{~m}$ (male, 1.54 - $1.82 \mathrm{~m}$, female, $1.48-1.74 \mathrm{~m}$ ). Table 1 and 2 showed comparison of mean weight and height between male and female analysis was made using independent ' $t$ ' test, which showed a significant difference with male subjects having greater

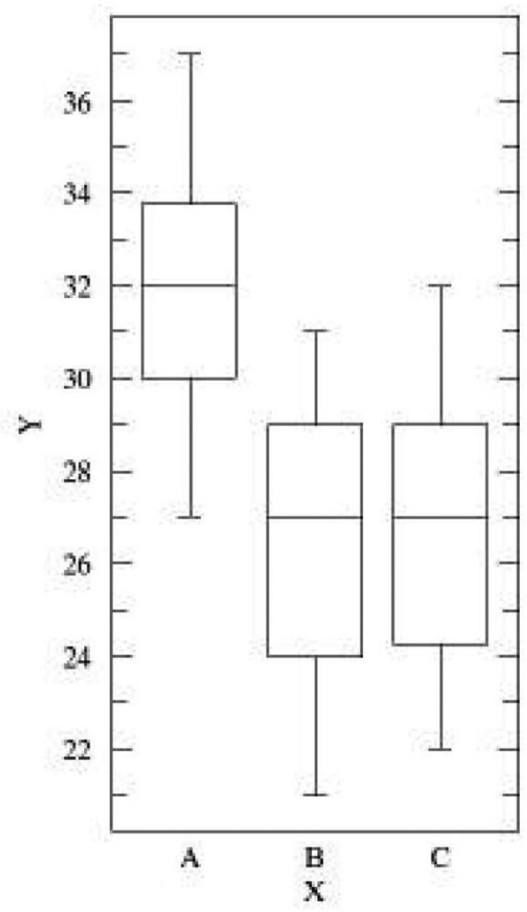

Figure 2. (Female) $\mathrm{X}$ axis- $\mathrm{H}-\mathrm{N}$ position, $\mathrm{A}$ : rotation to left; $\mathrm{B}$ : neutral; $\mathrm{C}$ : rotation to right; $\mathrm{Y}$ axis- grip strength in Kgs. 
Table 5. Pair-Wise Comparisons via Tukey HSD Test

\begin{tabular}{|c|c|c|}
\hline & Neutral & Head rotation to right \\
\hline Head rotation to left & Significant at $\mathrm{P}<0.01$ & Significant at $\mathrm{P}<0.01$ \\
\hline Neutral & & Not significant \\
\hline
\end{tabular}

mean height and weight than female subjects.

Table 3, 4 and Figure 1and 2 show the mean values of maximal grip strength at different $\mathrm{H}-\mathrm{N}$ positions. The mean maximal grip strength was compared using ANOVA, which reveals a significant difference in mean maximal grip strength across the three H-N positions in male and female participants $(\mathrm{P}<0.05)$.

Table 5 showed the turkey HSD analysis; reveal the significant difference which lies across the three different $\mathrm{H}-\mathrm{N}$ positions. There were significant differences in mean maximal grip strength between neutral vs. left rotation, and right rotation vs. left rotation in all the subjects.

\section{Discussion}

One of the important components in evaluating hand function is grip strength. It provides an objective index of the functional integrity of the upper extremity [15]. Grip strength is also an important component of hand rehabilitation as it is a measure of the effectiveness of therapy. Grip strength has in addition been used as a bedside tool to predict the development of postoperative complications in the fracture neck of femur and vascular surgeries [16].

We found that the mean did change as the H-N position changed. Although these changes were minimal, as we anticipated, some were significant. For male and female, $\mathrm{H}-\mathrm{N}$ rotation left slightly exceeded the mean reading when compared with $\mathrm{H}-\mathrm{N}$ rotation right and neutral. This finding parallels that of George, who found that TNR approached the predicted change when working with right-handed subjects.

Empirical observations suggest that neurally-based synergistic patterns could be elements of intentional as well as automatic action performed in limbs. The neuromotor synergy hypothesis postulates that low-level, neurally based patterns significantly constrain intentional actions. The hypothesis implies that a wide range of coordinated intentional actions can be generated by recruiting, suppressing, and/or modulating sets of neuro $\neg$ motor synergies, or networks subserving synergies [17]. Our data pertinent to the hypotheses that postural or neck reflexes significantly constrain intentional actions are evaluated in light of this proposed criteria.

Most studies attempting to show that cervico-spinal re- flexes significantly influence intentional movements. Consider Easton's suggestion that neck reflexes are critical to an animal's ability to make simple standing up or turning motions (1978). He argued that a horse's inability to stand up when its head held to the ground illustrated "obligatory reflex chaining" via cervico-spinal reflexes [18].

Secondly, task demands also need to be considered before arguing strongly that synergies like neck reflexes are significant constraints on voluntary action. Fukuda tried to argue from anecdotal observations of daily life and sports movements that neck and/or vestibular reflexes are important in shaping those actions. Consider the case of an archer drawing a bow, which Fukuda used to suggest the involvement of the ATNR in intentional action [19]. Task analysis shows that extension of the "face" arm provides a stable mechanical base against which to pull, while at the same time providing a sighting line to the target. These mechanical and perceptual factors seem more probable determinants of an archer's posture than neural constraints due to cervico-spinal reflex activation.

Thirdly, network models, which consist of interconnected systems of elements (nodes), have been used to model processes as diverse as sensory processes, linguistic behavior, and typing [20, 21]. Connections between nodes have direction, strength, and sign (plus or minus, roughly analogous to neural facilitation and inhibition). These properties of connectivity permit varied degrees of influence between a node and its neighbors. The provision on input (energy) to nodes is termed driving the nodes to reflect the external source of changes in node values. Considering this model, assumptions can be made to have connection nodes between cervical and arm movements.

Fourthly, researchers have attempted to show modulation of arm movements by vestibulo-spinal or cervico-spinal synergies by describing extraneous motions, movement errors, or static or dynamic changes in arm movements associated with changes in head posture. For example, changes in the orientation of vertical writing have been reported after vestibular stimulation and with the head rotated laterally, forward, or backward [22]. Figures from those studies showed that writing deviated from the vertical in directions consistent with experimentally induced vestibular stimulation or head postures.

Hellebrandt and her colleagues showed effects of head 
posture on isometric wrist extensions and flexions made at high, fatiguing levels of contraction. Fatigue and high force levels were used because the putative effects of neck reflexes on voluntary wrist movements could only be observed under those conditions. Hellebrandt and her colleagues proposed to explain associated head movements seen during production of high isometric forces at the wrist, operates differently. On this model, the arm flexor muscles are presumed to be intentionally activated via node. Then, afferent input from the arms could activate the (ventral) tonic neck synergy by hypothesized propriospinal pathway.

Though with few supportive studies, unfortunately, the current data are insufficient to provide a conclusive answer to the general question, "Do neuromotor synergies provide a basis for intentional action/grip strength?" Even for the more specific hypotheses regarding postural or neck reflex synergies as constraints on intentional action, available data are too fragmented to afford a clear empirical resolution of the question. Therefore, although neural processes and structures obviously are involved in generating automatic and intentional actions, it remains an open question as to whether neuromotor synergies as described will ultimately prove a useful construct in faciliatating intentional actions.

\section{Conclusions}

According to the findings of this study, we concluded that $\mathrm{H}-\mathrm{N}$ position may influence the grip strength. Apparently, $\mathrm{H}-\mathrm{N}$ rotation to the left on right hand dominant subjects may have a greater influence than neutral and $\mathrm{H}-\mathrm{N}$ rotated to right. Reduced upper limb strength capacity in females could be a reason that the influence of ATNR may be elicited more easily in female subjects than in male subjects.

\section{Clinical implications}

This study suggests that during the assessment of maximal grip strength, the $\mathrm{H}-\mathrm{N}$ be rotated opposite to the testing upper extremity. These results have implications for evaluation and rehabilitation approaches used by therapists.

\section{Acknowledgement}

We wish to acknowledge ASEAN Metropolitan University College for its continued support in research endeavors. We are grateful to Dato' Prof. DR. Ahmad Pauzi Bin Md Yusof, Prof DR. Noor Aini Mohd Yusoff, and Assoc Prof Muthappan for their support and encouragement.

\section{Disclosure}

We have no conflicts to disclose.

\section{References}

1. Magnus R, de Kleijn A: The influence of the position of the head on the tone of the muscles of the extremities. Pflugers Arch 145:455-548, 1912. http://dx.doi. org/10.1007/BF01681127

2. Fukuda T. Studies on human dynamic postures from the viewpoint of postural reflexes. Acta Otolaryngol Suppl. 1961;161:1-52.

3. George C. Facilitative and inhibitory effects of the tonic neck reflex upon grip strength of right- and left-handed children. Res Q. 1972;43(2):157-166.

4. Parmenter CL. The asymmetrical tonic neck reflex in normal first and third grade children. Am J Occup Ther. 1975;29(8):463-468.

5. Wells HS. The Demonstration of Tonic Neck and Labyrinthine Reflexes and Positive Heliotropic Responses in Normal Human Subjects. Science. 1944;99(2559):3637.

6. Ikai M, Tonic neck reflex in normal persons. Jap J Physiol 1: US 124,1950

7. Tokizane T, Murao M, Ogata T, Kondo T. Electromyographic studies on tonic neck, lumbar and labyrinthine reflexes in normal persons. Jpn J Physiol. 1951;2(2):130146.

8. Hellebrandt FA, Houtz SJ, Partridge MJ, Walters CE. Tonic neck reflexes in exercises of stress in man. Am J Phys Med. 1956;35(3):144-159.

9. Geddes D, O’Grady W. Manifestation of tonic neck reflexes in normal adults during physical activity. Am Correct Ther J. 1979;33(6):184-187.

10. Long C, 2nd, Conrad PW, Hall EA, Furler SL. Intrinsicextrinsic muscle control of the hand in power grip and precision handling. An electromyographic study. J Bone Joint Surg Am. 1970;52(5):853-867.

11. Desrosiers J, Bravo G, Hebert R, Mercier L. Impact of elbow position on grip strength of elderly men. J Hand Ther. 1995;8(1):27-30.

12. Fong PW, Ng GY. Effect of wrist positioning on the repeatability and strength of power grip. Am J Occup Ther. 2001;55(2):212-216.

13. Mathiowetz V, Weber K, Volland G, Kashman N. Reliability and validity of grip and pinch strength evaluations. J Hand Surg Am. 1984;9(2):222-226.

14. Myers CR, Golding LA, Sinning WE. The Y' way to physical fitness. 1. Emmaus: Rodale Press Inc; 1973. pp. 49-50.

15. Davies CW, Jones DM, Shearer JR. Hand grip--a simple test for morbidity after fracture of the neck of femur. J R Soc Med. 1984;77(10):833-836.

16. Lee WA. Neuromotor synergies as a basis for coordinated intentional action. J Mot Behav. 1984;16(2):135-170.

17. Easton, T. A. Coordinative structures - the basis for a motor program. Psychology of motor behavior and 
sport, pp. 63-01, Champaign, Illinois: Human Kinetics Publishers, 1978

18. Fukuda T. Vertical writing with eyes covered; a new test of vestibulo-spinal reaction. Acta Otolaryngol. 1959;50(1):26-36.

19. Brazier, M. A., Waller, D. O., \& Schneider, D. Neural modeling, Los Angeles: UCLA Brain Research Institute,
1973.

20. Feldman AG. Superposition of motor programs--I. Rhythmic forearm movements in man. Neuroscience. 1980;5(1):81-90.

21. Waterland JC, Doudlah AM, Shambes GM. The influence of the tonic neck reflex: vertical writing. Acta Otolaryngol. 1966;61(4):313-322. 